\title{
USE OF HYDROXYCHLOROQUINE IN COMBINATION WITH STATINS AS AN LDL LOWERING AGENT IN PATIENTS OF TYPE II DM WITH DIABETIC NEPHROPATHY
}

\author{
Shri Krishna Gautam¹, Jitendra Singh Kushwaha², Harshit Khare³, Brijesh Kumar
}

${ }_{1}^{1}$ Associate Professor, Department of Medicine, GSVM Medical College, Kanpur, U. P.

2Professor, Department of Medicine, GSVM Medical College, Kanpur, U. P.

3Junior Resident, Department of Medicine, GSVM Medical College, Kanpur, U. P.

${ }_{4}^{4}$ Associate Professor, Department of Medicine, GSVM Medical College, Kanpur, U. P.

ABSTRACT

\section{BACKGROUND}

Statins have established themselves as one of the best choice for lowering LDL levels, and have recently been proved efficacious for reducing albuminuria significantly. However, with the latest bar for target LDL levels set at $50 \mathrm{mg} / \mathrm{dl}$, we definitely need to look for other ways of lowering LDL especially in population of Diabetics Nephropathy who are not only at high risk for CV mortality but also need dosage reduction due to impaired renal function. With the recent DGI approval of HCQS (hydroxychloroquine) for use as an antidiabetic drug, we decided to explore the effects of HCQS in combination with atorvastatin on Lipid profile of pati ents with Diabetic Nephropathy. Our study showed that combining HCQS with Atorvastatin results in even better control of LDL levels with favourable effect on other lipids as well.

\section{MATERIALS AND METHODS}

This is a non -randomised controlled study. A total of 67 patients with Type II Diabetes Mellitus (in the age group of 30-80yrs, with clinical evidence of Diabetic Kidney Disease [DKD], HbA1c $\geq 6.5$ ) were selected among admitted the patients of the K.P.S. P.G. Institute of Medicine at LLR \& Associated Hospital, G.S.V.M. Medical College Kanpur and alternatively divided into two groups with one group taking Hydroxychloroquine (100mg b.i.d.) in addition to their regular medications. Both groups were then looked for any significant changes in their lipid profiles after 3 months.

\section{RESULTS}

In our study, while triglyceride levels were reduced by $24.69 \%$ and $10.66 \%$ in the Hydroxychloroquine and NonHydroxychloroquine group respectively, both of which were statistically significant, Low density Lipid-cholesterol levels were reduced by $10.24 \%$ in Hydroxychloroquine group while these levels continued to increase by $14 \%$, in the NONHydroxychloroquine group, after a follow up of 3 months. Also although the total cholesterol declined in both the groups after 3 months but, decline was more with HCQS group. And while HDL increased significantly with the HCQS group after 3 months, it was not significant in the NON-HCQS group.

\section{CONCLUSION}

While the NON-HCQS group (On atorvastatin 20mg alone) observed decline in TGs and Cholesterol, their HDL did not rise and LDL continued to rise after 3 months of treatment. However, in the HCQS group (On combination of HCQS 100mg bd and atorvastatin $20 \mathrm{mg} \mathrm{h} / \mathrm{s}$ ), HDL was seen increased with significant decline in LDL and TG after 3 months of treatment stating that the combination of HCQS with statins may be a better choice for lowering lipids in DKD patients than using statins alone.

\section{KEYWORDS}

Diabetic Nephropathy, Hydroxychloroquine, LDL.

HOW TO CITE THIS ARTICLE: Gautam SK, Kushwaha JS, khare H, et al. Use of hydroxychloroquine in combination with statins as an LDL lowering agent in patients of type II DM with diabetic nephropathy. J. Evolution Med. Dent. Sci. 2018;7(09):1152-1156, DOI: $10.14260 /$ jemds/2018/262

\section{BACKGROUND}

Statins significantly reduce lipid concentrations and cardiovascular end points in patients with chronic kidney disease but to a lesser degree than in general population. However, their less proven renal safety limits their use in Chronic kidney disease and Diabetic Kidney disease patients and even their benefit on all cause mortality in such patients remains to be established. ${ }^{1}$

'Financial or Other Competing Interest': None.

Submission 31-01-2018, Peer Review 18-02-2018,

Acceptance 20-02-2018, Published 26-02-2018.

Corresponding Author:

Dr. Jitendra Singh Kushwaha,

H. N. 7/190-E, Swaroop Nagar,

Kanpur-208002, U.P.

E-mail: drjskushwaha@gmail.com

DOI: $10.14260 /$ jemds $/ 2018 / 262$
Similarly there are studies stating that the dyslipidaemia prevalent in such patients is also less likely to respond to statins. All this had generated a need for better treatment option for lowering lipid levels especially the LDL levels in DKD patients without impairing their renal function.

This brought our attention to HCQS, which in combination with atorvastatin could be of benefit in reducing dyslipidemia in a more better way in Diabetic kidney disease patients. ${ }^{2,3}$ Our view has been supported partly by a study in Lupus Nephritis patients where HCQ treatment was associated with reduced severity of dyslipidaemia in LN patients. 4,5

\section{Objective}

To investigate the effectiveness of hydroxychloroquine in dosage of $100 \mathrm{mg}$ bd in combination with atorvastatin (20mg) as a LDL lowering agent in patients of Diabetic Nephropathy 


\section{MATERIALS AND METHODS}

Sixty seven patients of Type II Diabetes mellitus, irrespective of sex, in the age group of 30-80 yrs, with clinical evidence of Diabetic Kidney Disease [DKD], were selected from set of patients admitted and willing to give consent in the K.P.S. P.G. Institute of Medicine at LLR \& Associated Hospital, GSVM Medical College, Kanpur from December 2015 to October 2017.

\section{Diabetic Kidney Disease was defined as-}

1. Either having Class II-V of kidney disease on histopathology in renal biopsy or proteinuria $\geq 0.5 \mathrm{~g}$ per 24 hours or $3+$ proteinuria without UTI; or

2. One of the following features also attributable to DKD and present on two or more visits performed at least 3 months apart: proteinuria $\geq 2+$, creatinine clearance $\leq 90$ $\mathrm{ml} / \mathrm{min}, \geq 10$ RBCs or WBCs per high power field (hpf), or $\geq 3$ granular or cellular casts per hpf or microalbuminuria.

\section{Study Design}

Non -randomised controlled study

\section{Study Period}

December 2015 to May 2017

\section{Place of Study}

Inpatient \& Outpatients of department of Medicine, at LLR \& Associated Hospital, GSVM Medical College, Kanpur.

\section{Inclusion Criteria}

- $\quad$ Patients with history of Diabetes Mellitus type II for at least 5 yrs, with Diabetic kidney Disease [DKD],

- Defined as urinary albumin excretion of 30-299 mg/24 hours in a 24-hour urinary collection or

- 20-199 microgram/min in a timed urine collection, or

- 30-299 miocrogram/mg creatinine in a spot urine collection on at least two occasions; Or

- $\quad$ eGFR $<90 \mathrm{~mL} / \mathrm{min} / 1.73 \mathrm{~m} \mathrm{2}$,

- With $\mathrm{HbA1C}>6.5$, age between 30 to $80 \mathrm{yrs}$,

- With/without documented medical renal disease on abdominal ultrasonography.

\section{Exclusion Criteria}

- DKD patients on maintenance hemodialysis.

- DKD patients with symptoms/ signs of uremia. Dkd with history of Congestive Heart Failure (CHF) or currently with symptoms and signs of CHF.

- DKD with history of coronary artery disease.

- $\quad$ DKD with Left Ventricle Ejection Fraction (LVEF) < 30\%

- DKD with proliferative retinopathy or nonproliferative Retinopathy with age $>60 \mathrm{yr}$.

- DKD patients who had on going urinary tract infection with pus cells in urine.

The patients were alternatively divided into two groups. One group on HCQS $100 \mathrm{mg}$ twice daily with rest of the medication while other group without HCQS continuing on rest of the medications.

Patients were investigated at intitial visit to the LLR Hospital and then after 3 months.
Dosage of short acting Insulin was adjusted to maintain good glycaemic from then onwards. Those found hypertensive were also given antihypertensive drugs which included amlodipine/nifidipine/ moxinidine. Both the groups had near about equal number of such patients.

\section{Investigation-}

At Start of Study and following 3 Months into Study each Patient was investigated for the following -

- HbA1c.

- Serum lipid profile.

- Blood sugar.

- Fasting.

- Post prandial.

- Serum creatinine level.

- Serum Urea.

- Liver Function Test.

- USG whole abdomen.

- Urine Routine and microscopic examination.

- Urine albumin creatinine ratio.

- ECG and 2D-Echo.

- $\quad$ CT abdomen if required.

At each visit, body weight and blood pressure were measured and fasting blood samples were collected for the measurement of above investigations.

We screened the Type II Diabetic patients with history, symptoms and signs of Nephropahty, from the general population of Type II Diabetics, using predecided Inclusion and Exclusion criteria (Discussed in Material and Methods).

They were then alternatively divided into two Groups, with one group taking Hydroxychloroquine in dosage of $100 \mathrm{mg}$ twice daily along with their rest of the medication.

Rest of the Medication included Short acting Insulin, Amlodipine/ Nifedipine, Atorvastatin in dosage of $20 \mathrm{mg}$, Toresamide $10 \mathrm{mg}$, Vit D preparations, Calcium preparations and Angiotension Converting Enzyme Inhibitors (Ramipril).

The other group (Non-Hydroxychloroquine group) continued with rest of the medications based on short acting insulin without Hydroxychloroquine.

Both groups were followed for next 3 months and serial changes in their s. creatinine, eGFR, Urine ACR, HbA1C, BS-F, PP, LDL, HDL, TG were noted.

The total number of patients on ramipril in both the groups were 16/31 in the Hydroxychloroquine group and $22 / 36$ in the non-Hydroxychloroquine group, respectively based on whether their eGFR permitted use of ramipril or not.

Total 4 patients were withdranwn from ramipril during the period of study ( 2 in each group) as their eGFR declined.

\section{Grouping of Cases}

Patients after Screening, were selected for the Study and were Alternatively, Grouped as follows Group I (Hydroxychloroquine/ HCQS Group/ Cases)

Patients with established DKD, who gave consent and were willing to take HCQS in the dosage of $100 \mathrm{mg}$ twice daily for at least 3 months, in addition to their other medications. 


\section{Group 2 (Non-Hydroxychloroquine/ Non-HCQS Group/ Controls)}

Patients with established DKD, who were not given HCQS for the same duration of time in addition to their regular medication.

Each patient had a baseline or enrolment visit (T0) followed by a 3 month visit (T3). Time of screening (Ts) was defined as the time when each patient met for ACR criteria. Each visit included interview, physical examination, and laboratory tests.

Additional clinical information covering the period between scheduled visits as well as data for missed study visits were obtained by review of all available medical records.

None of the patients had episodes of hypoglycaemia since the diagnosis of Type II Diabetes upto present and during the period of the study.

All patients were on short acting insulin with dosage modified according to daily insulin need and changes in insulin requirement with changing renal function. They had been on short acting insulin for at least 3months prior to the study.
During the study all were recommended and advised to take a diet consisting of $30 \mathrm{kcal}$ per kg ideal body weight, 50 $55 \%$ carbohydrate, $30 \%$ fat, $15-20 \%$ protein and $300 \mathrm{mg}$ cholesterol which was reinforced during the period of the study in both the groups.

Patients in both the groups were taking atorvastatin $20 \mathrm{mg}$ as hypolipidaemic drugs, during the period of study, in low risk dose.

Four patients withdrew from the study after 3 months, three could not attend the frequent follow-up due to personal reasons and another emigrated.

None of the patients in either group went for hemodialysis during or before the period of study.

\section{Statical Analysis}

The data was assembled using Mac Numbers version 4.3.1 and analysed using SPSS version 23.Unpaired $\mathrm{T}$ test was applied to compare baseline characterstics of two groups and later paired $\mathrm{T}$ test was applied to determine change in both groups over study period of 3 months.

\section{RESULTS}

The clinical characteristics of the 67 patients who completed the 3 months study, are summarised in Table 1.

\begin{tabular}{|c|c|c|c|c|c|c|}
\hline \multicolumn{7}{|c|}{ Group Statistics } \\
\hline & CODE & $\mathbf{N}$ & Mean & Std. Deviation & Std. Error Mean & p Value \\
\hline \multirow{2}{*}{ HbA1c. T0 } & 1 & 29 & 9.26 & 2.196 & 0.408 & .091 \\
\hline & 2 & 36 & 9.52 & 1.549 & 0.258 & \\
\hline \multirow{2}{*}{ S. CREA. T0 } & 1 & 31 & 2.01 & 0.878 & 0.158 & .701 \\
\hline & 2 & 36 & 1.56 & 1.000 & 0.167 & \\
\hline \multirow{2}{*}{ eGFR. T0 } & 1 & 31 & 39.95 & 23.764 & 4.268 & .808 \\
\hline & 2 & 36 & 55.99 & 23.867 & 3.978 & \\
\hline \multirow{2}{*}{ BS-F. T0 } & 1 & 29 & 214.73 & 84.904 & 15.766 & .451 \\
\hline & 2 & 36 & 227.13 & 44.357 & 7.393 & \\
\hline \multirow{2}{*}{ BS-PP. T0 } & 1 & 28 & 320.96 & 104.283 & 19.708 & .944 \\
\hline & 2 & 36 & 319.49 & 63.225 & 10.537 & \\
\hline \multirow{2}{*}{ U. ACR. T0 } & 1 & 31 & 1210.206 & 535.0952 & 96.1059 & .085 \\
\hline & 2 & 36 & 929.414 & 460.8613 & 76.8102 & \\
\hline \multirow{2}{*}{ CHO. T0 } & 1 & 18 & 177.87 & 46.623 & 10.989 & 0.840 \\
\hline & 2 & 36 & 175.89 & 26.082 & 4.347 & \\
\hline \multirow{2}{*}{ TG. T0 } & 1 & 18 & 183.96 & 109.797 & 25.879 & .379 \\
\hline & 2 & 36 & 202.91 & 29.833 & 4.972 & \\
\hline \multirow{2}{*}{ HDL. T0 } & 1 & 18 & 57.61 & 20.191 & 4.759 & .292 \\
\hline & 2 & 36 & 41 & 7.724 & 1.287 & \\
\hline \multirow{2}{*}{ LDL. T0 } & 1 & 18 & 81.67 & 42.763 & 10.079 & .115 \\
\hline & 2 & 36 & 93.40 & 15.640 & 2.607 & \\
\hline & & & 1. Basel & terstics $^{6}$ & & \\
\hline
\end{tabular}

Code 1 = Hydroxychloroquine group.

Code 2 = Non-hydroxychloroquine group.

There was no significant difference between Hydroxychloroquine Group and NON-Hydroxychloroquine Group patients in any of the clinical characteristics at baseline (Table 1).

\begin{tabular}{|c|c|c|c|}
\hline Groups/Time & $\begin{array}{c}\text { Mean LDL } \\
\text { with SD } \\
\text { T0 }\end{array}$ & $\begin{array}{c}\text { Mean LDL } \\
\text { with SD } \\
\text { T3 }\end{array}$ & $\begin{array}{c}\text { P } \\
\text { value }\end{array}$ \\
\hline \multirow{2}{*}{ Hydroxychloroquine } & $\begin{array}{c}81.67 \pm \\
42.76\end{array}$ & $\begin{array}{c}73.06 \pm \\
36.82\end{array}$ & .001 \\
\hline Non-hydroxychloroquine & $\begin{array}{c}93.40 \pm \\
15.64\end{array}$ & $\begin{array}{c}106.62 \pm \\
15.85\end{array}$ & .001 \\
\hline \multicolumn{2}{|c|}{ Table 2. LDL mean change over 3 months } \\
\hline
\end{tabular}

For Hydroxychloroquine group, LDL mean value was 81.67 initially at start of study, with SD of \pm 42.763 and after 3 months, LDL mean value was 73.06 , with $\mathrm{SD} \pm 36.825$. Paired $t$ test was applied and $\mathrm{p}$ value was $<0.001$, indicating the decline in LDL was highly significant.

For the Non-Hydroxychloroquine group, LDL mean value was 93.40 initially at start of study, with SD of \pm 15.640 and after 3 months, LDL mean value was 106.62 , with SD \pm 15.849 . Paired t test was applied and $p$ value was $<0.001$, indicating 
the increase in LDL, was highly significant in the NON-HCQS group. (Table 2, Figure 1)

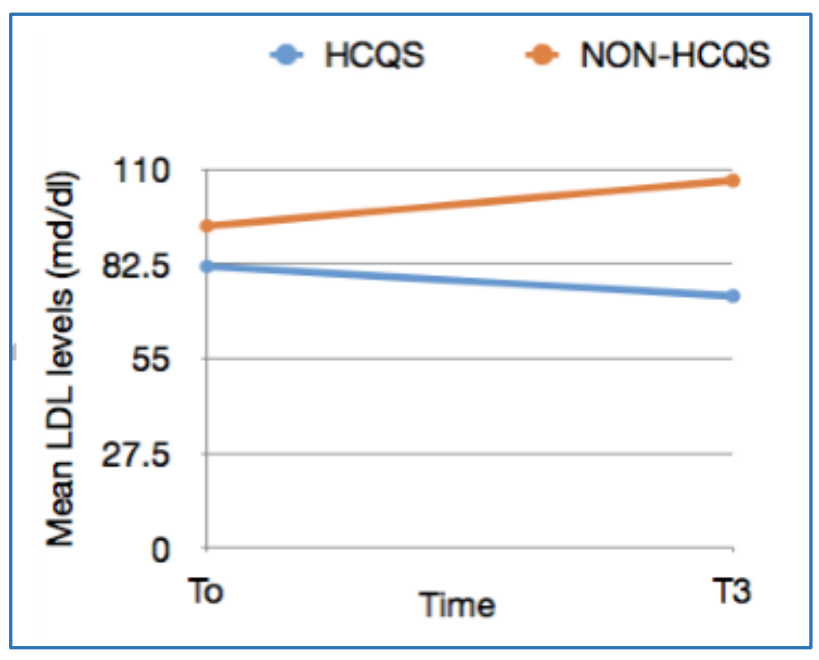

Figure 1. LDL Mean Change over 3months

For Hydroxychloroquine group, Cholesterol mean value was 177.87 initially at start of study, with SD of \pm 46.725 and after 3 months, Cholesterol mean value was 163.62, with SD \pm 44.869 . Paired $t$ test was applied and $p$ value was $<0.001$, indicating the decline in Cholesterol was highly significant.

For the Non-Hydroxychloroquine group, Cholesterol mean value was 175.89 initially at start of study, with SD of \pm 25.125 and after 3 months, Cholesterol mean value was 173.73 , with SD \pm 33.331 . Paired $t$ test was applied and $p$ value was $<0.001$, indicating the decline in Cholesterol, was highly significant in the Non-Hydroxychloroquine group. (Table 3, Figure 2).

\begin{tabular}{|c|c|c|c|}
\hline Groups/Time & $\begin{array}{c}\text { Mean } \\
\text { Cholesterol } \\
\text { with SD T0 }\end{array}$ & $\begin{array}{c}\text { Mean } \\
\text { Cholesterol } \\
\text { with SD T3 }\end{array}$ & $\begin{array}{c}\text { P } \\
\text { value }\end{array}$ \\
\hline Hydroxychloroquine & $\begin{array}{c}177.87 \pm \\
46.72\end{array}$ & $\begin{array}{c}163.62 \pm \\
44.87\end{array}$ & .001 \\
\hline \multicolumn{2}{|c|}{ Non- } & $175.89 \pm$ & $173.73 \pm$ \\
hydroxychloroquine & 25.12 & 33.33 & .001 \\
\hline \multicolumn{3}{|c|}{ Table 3. Cholesterol Mean Change Over 3 Months } \\
\hline
\end{tabular}

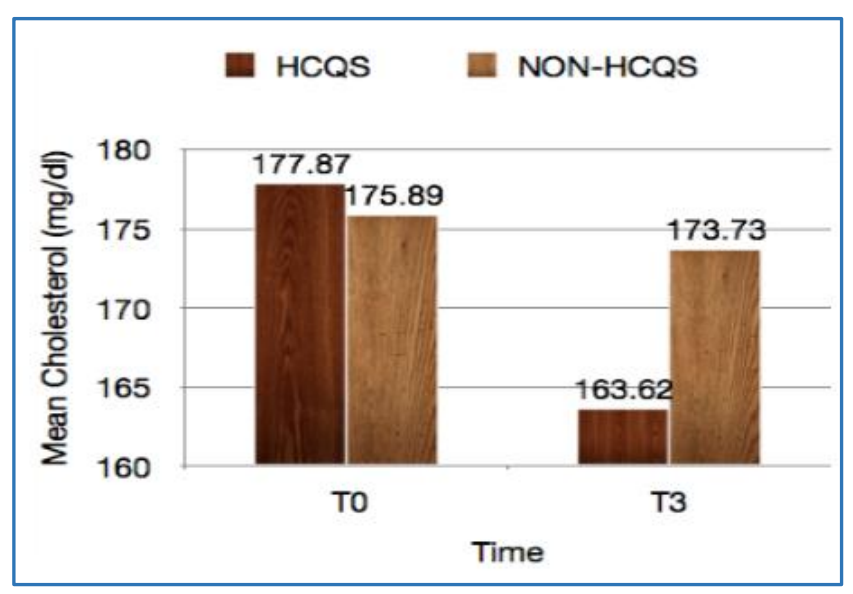

Figure 2. Cholesterol (CHO) Mean Change Over 3 Months

\begin{tabular}{|c|c|c|c|}
\hline Groups/Time & $\begin{array}{c}\text { Mean } \\
\text { Triglyceride } \\
\text { with SD T0 }\end{array}$ & $\begin{array}{c}\text { Mean } \\
\text { Triglyceride } \\
\text { with SD T3 }\end{array}$ & $\begin{array}{c}\text { P } \\
\text { value }\end{array}$ \\
\hline Hydroxychloroquine & $\begin{array}{c}183.96 \pm \\
109.79\end{array}$ & $\begin{array}{c}138.54 \pm \\
69.82\end{array}$ & .001 \\
\hline \multicolumn{2}{|c|}{ Non- } & $202.91 \pm$ & $181.26 \pm$ \\
hydroxychloroquine & 29.33 & 32.73 & .001 \\
\hline \multicolumn{4}{|c|}{ Table 4. Triglyceride Mean Change Over 3 Months } \\
\hline
\end{tabular}

For Hydroxychloroquine group, Triglyceride levels mean value was 183.96 initially at start of study, with SD of \pm 109.797 and after 3 months, Triglyceride levels mean value was 138.54 , with $\mathrm{SD} \pm 69.820$. Paired t test was applied and $p$ value was $<0.001$, indicating the decline in Triglyceride levels was highly significant.

For the Non-Hydroxychloroquine group, Triglyceride levels mean value was 202.91 initially at start of study, with SD of \pm 29.833 and after 3 months, Triglyceride levels mean value was 181.26 , with $S D \pm 32.731$. Paired t test was applied and $\mathrm{p}$ value was $<0.001$, indicating the decline in Triglyceride levels, was highly significant in the Non-Hydroxychloroquine group also. (Table 4, Figure 3).

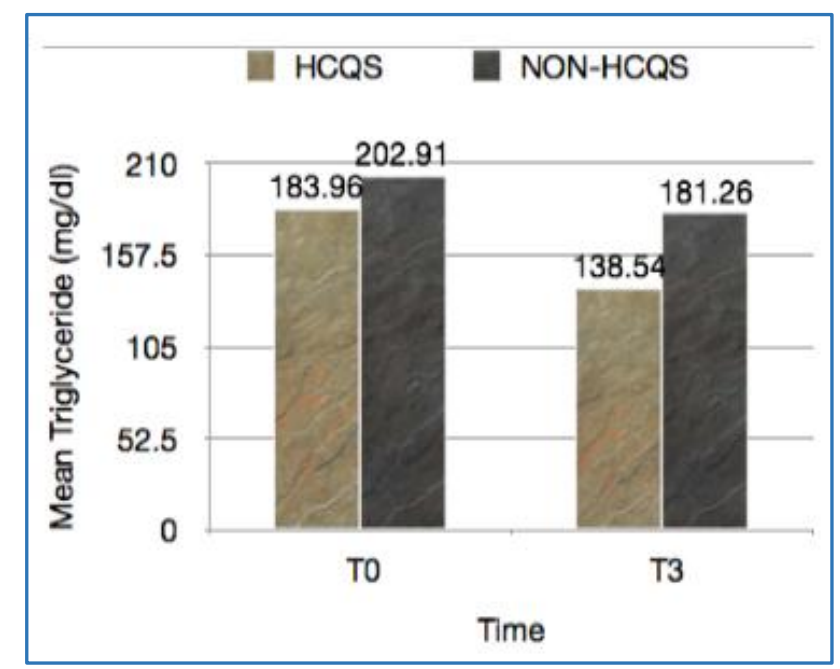

Figure 3. Triglyceride (TG) mean change over 3 months

\begin{tabular}{|c|c|c|c|}
\hline Group/time & $\begin{array}{c}\text { Mean HDL } \\
\text { with SD } \\
\text { T0 }\end{array}$ & $\begin{array}{c}\text { Mean HDL } \\
\text { with SD } \\
\text { T3 }\end{array}$ & $\begin{array}{c}\text { P } \\
\text { value }\end{array}$ \\
\hline \multirow{2}{*}{ Hydroxychloroquine } & $\begin{array}{c}57.61 \pm \\
20.91\end{array}$ & $\begin{array}{c}60.50 \pm \\
19.04\end{array}$ & .001 \\
\hline Non-hydroxychloroquine & $\begin{array}{c}41 \pm \\
7.72\end{array}$ & $\begin{array}{c}47.02 \pm \\
5.99\end{array}$ & .077 \\
\hline \multicolumn{3}{|c|}{ Table 5. HDL mean change over 3 months } \\
\hline
\end{tabular}

For Hydroxychloroquine group, HDL levels mean value was 57.61 initially at start of study, with SD of \pm 20.191 and after 3 months, HDL levels mean value was 60.50, with SD \pm 19.049 . Paired $t$ test was applied and $p$ value was $<0.001$, indicating the increase in HDL levels was highly significant.

For the Non-Hydroxychloroquine group, HDL levels mean value was 41.0 initially at start of study, with SD of \pm 7.724 and after 3 months, HDL levels mean value was 47.02, with $\mathrm{SD} \pm 5.998$. Paired t test was applied and $\mathrm{p}$ value was 0.077 , indicating the increase in HDL levels, was not significant in the Non-Hydroxychloroquine group. (Table 5, Figure 4). 


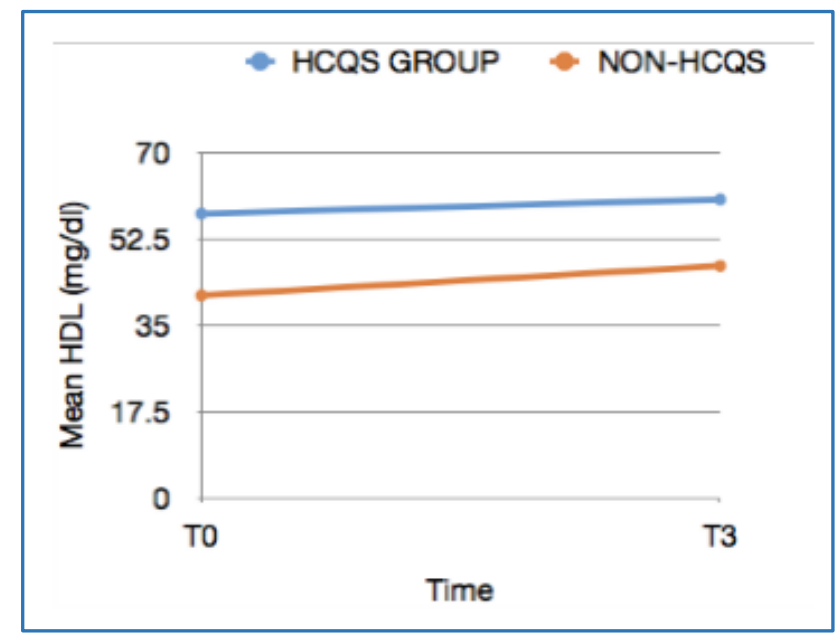

Figure 4. HDL mean change over 3 months

After that, we did a comparison between the mean end points of two groups (HCQS and Non-HCQS) at the end of 3 months by independent $t$ test, where we compared end point LDL, HDL, TGs and total Cholesterol. We obtained the following results-

\begin{tabular}{|c|c|c|}
\hline & Mean \pm SD & P value \\
\hline $\begin{array}{c}\text { Cholesterol } \\
\text { HCQS } \\
\text { NON-HCQS }\end{array}$ & $\begin{array}{l}161.49 \pm 45.168 \\
174.51 \pm 33.188\end{array}$ & 0.132 \\
\hline $\begin{array}{c}\text { Triglycerides } \\
\text { HCQS } \\
\text { NON-HCQS }\end{array}$ & $\begin{array}{l}135.84 \pm 70.822 \\
181.42 \pm 32.274\end{array}$ & 0.032 \\
\hline $\begin{array}{c}\text { HDL } \\
\text { HCQS } \\
\text { NON-HCQS }\end{array}$ & $\begin{array}{l}60.53 \pm 19.601 \\
47.38 \pm 50.281\end{array}$ & 0.02 \\
\hline $\begin{array}{c}\text { LDL } \\
\text { HCQS } \\
\text { NON-HCQS }\end{array}$ & $\begin{array}{c}70.59 \pm 36.232 \\
106.92 \pm 20.129\end{array}$ & 0.006 \\
\hline Table 6. Con & son between Gro & 3month \\
\hline
\end{tabular}

\section{DISCUSSION}

Role of HCQS in regression of Db Nephropathy in DKD patients can be explained by its action via several mechanism, one of which is making lipid profile favourable, 2,6 which we tried to find out in our study.

Statistical analysis showed that there was no significant difference between HCQS-group and NON-HCQS group patients in terms of $\mathrm{HbA1c}$, s. creatinine, and eGFR at baseline (Table 1)

We found that Hydroxychloroquine group, compared to Non-Hydroxychloroquine Group, benefitted in terms of their lipid profile changes.

While TG was reduced in both the groups, $24.69 \%$ and $10.66 \%$ in the HCQS and NON-HCQS group respectively, both of which were statistically significant (Table 4, Figure 3), the LDL-cholesterol was reduced by $10.24 \%$ in HCQS group while it continued to increase by $14 \%$, in the NON-HCQS group, after a follow up of 3 months. (Table 2, Figure 1).

Also, although total cholesterol declined in both the groups (Table 3, Figure 2), it was more in the HCQS group.

Also, the rise of HDL was only significant only in the HCQS group (Table 5, Figure 4)
By another way of comparison by independent $t$ test between two groups at the end of study, there were significant differences between the changes of mean between the two groups.

The HCQS Group had significantly lower levels of LDL and TG and significant increase in the HDL levels while Cholesterol levels were not significantly changed between the two groups. (Table 6)

These favourable Lipid Profile changes in the HCQS Group not only prove that its combination with atorvastatin is a better treatment option for dyslipidemia in DKD patients but may also explain why this drug is so effective in retarding the progression of Diabetic Nephropathy in such patients. ${ }^{6}$

This mechanism of reducing dyslipidemia in turn retrading Diabetic Nephropathy has been exemplified by some earlier studies too. $7,4,5$

Our study proved that HCQS in dosage of $100 \mathrm{mg}$ bd in combination with atorvastatin $20 \mathrm{mg}$ lowers LDL levels better than Atorvastatin $20 \mathrm{mg}$ alone in DKD patients.

\section{CONCLUSION}

To conclude, HCQS while an anti-malarial, may have effects that include lowering bad cholesterol (LDL) and favouring good cholesterol (HDL) along with regression of Diabetic nephropathy in the Diabetic kidney disease patients, which may also explain the reason of its effectiveness in retarding progression of nephropathy in such patients and it may be combined with Atorvastatin for better lowering of lipid levels and better control of dyslipidemia in the DKD patients.

\section{REFERENCES}

[1] Strippoli GF, Navaneethan SD, Johnson DW, et al. Effects of statins in patients with chronic kidney disease: metaanalysis and meta-regression of randomised controlled trials. BMJ 2008;336(7645):645-51.

[2] Jang $\mathrm{CH}$, Choi JH, Byun MS, et al. Chloroquine inhibits production of TNF-alpha, IL-1beta and IL-6 from lipopolysaccharide-stimulated human monocytes/ macrophages by different modes. Rheumatology (Oxford) 2006;45(6):703-10.

[3] Shukla AM, Bose C, Karaduta OK, et al. Impact of hydroxychloroquine on atherosclerosis and vascular stiffness in the presence of chronic kidney disease. PLoS One 2015;10(9):e0139226.

[4] Chong YB, Yap DY, Tang CS, et al. Dyslipidaemia in patients with lupus nephritis. Nephrology (Carlton) 2011;16(5):511-7.

[5] Sisó A, Ramos-Casals M, Bové A, et al. Previous antimalarial therapy in patients diagnosed with lupus nephritis: influence on outcomes and survival. Lupus 2008;17(4):281-8.

[6] Kushwaha JS, Gautam SK, Khare H. To study the use of hydroxychloroquine in small doses in regression of diabetic nephropathy in patients of type II diabetes mellitus. J Evolution Med Dent Sci 2018;7(03):346-50.

[7] Bernadet-Monrozies P, Rostaing L, Kamar N, et al. The effect of angiotensin-converting enzyme inhibitors on the progression of chronic renal failure. Presse Med 2002;31(36):1714-20. 